\title{
Evaluation of Biting Force of New Design of Extracoronal Castable Precision Attachment versus Conventional Partial Denture for Treatment of Unilateral Mandibular Distal Extension Area: A Randomized Controlled Trial
}

\author{
Mohamed Afify*, M. Helmy, N. Abbas \\ Department of Prosthodontic, Cairo University, Giza, Egypt
}

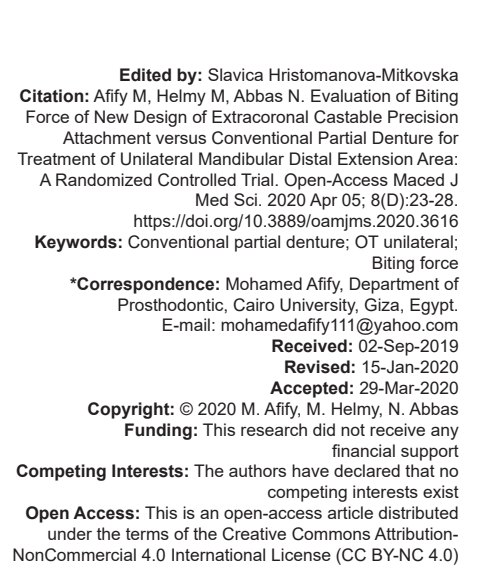

Introduction

In unilateral distal extension, there are disparities of support between hard and soft tissues, which create the movement of the prosthesis, with resultant harmful effects on underlying tissues and bone. When vertical forces are applied, it will be transmitted unevenly to the investing structures due to the difference in the resiliency of periodontal ligament of abutment teeth and denture bearing mucosa [1].

Rehabilitation of partially edentulous arch can be challenging when it is a distal extension situation classified under Kennedy's Class I and Class II situations [2], as rehabilitation of lost teeth with removable partial dentures (RPDs) is often utilized to improve patients' masticatory function, but patient satisfaction is important as patients with mandibular RPD complaining of impairment or functional limitations creating difficulties in daily life [3], [4], [5].

Implants can be planned, but it may be not feasible due to insufficient bone and economic reasons. Hence, acrylic denture or cast partial denture is largely preferred. Cast partial dentures are made retentive by retainers and precision attachment components [6]. Precision attachments could be extracoronal or intracoronal. Attachment-retained cast partial dentures improve both esthetic and function. Studies have shown a survival rate of $83.35 \%$ for 5 years, of $67.3 \%$ up to 15 years, and of $50 \%$ when extrapolated to 20 years [6], [7].

The attachment has long been considered the highest form of partial denture therapy. When selecting an attachment, the dentist wishes to use the best attachment in specific cases. There is probably no such thing as "best attachment" but there may be several attachments that will work equally well, so one should not select an attachment by the name rather by understanding basic principles which never changes as crown root ratio, vertical space available, number of teeth support, amount of bone, and location of strongest abutment [8].

OT extracoronal resilient attachment system offers vertical resiliency and universal stress relief for use where a resilient prosthesis is indicated. The RPD retained by these attachments provides esthetics, 
vertical resiliency, and easy replacement of worn attachments [9].

The target of this study is to figure mastication efficacy when alternating between the extracoronal attachment (OT unilateral attachment system) and conventional partial denture.

\section{Materials and Methods}

Sixteen patients were selected from the outpatient clinic of the Prosthodontic Department Clinic, Faculty of Dentistry, Cairo University, their age ranged from 35 to 55 years.

\section{Patient selection}

Patients with unilateral mandibular distal extension area with the second premolar were the last standing abutment that shows sufficient occlusogingival height of its clinical crown. Full opposing arch or restored with acceptable fixed restoration. Edentulous ridge covered by healthy firm mucoperiosteum, without abnormal bony irregularity or sever lingual undercut. The abutment teeth had apparently good periodontal condition with no signs of mobility or inflammation with no tissue undercut. Patients with the shallow floor of the mouth, prominent lingual tori, bony undercuts, and lingual inclined teeth were all excluded. Adequate interarch space and no tempromandibular joint disorders. Patients should have no history of parafunctional habits as bruxism. All patients were apparently in good general health, and free from systemic diseases as diabetes mellitus. Only patients who can be easily motivated to achieve and maintain good oral hygiene were selected.

This study was approved by the research ethics committee Faculty of Dentistry Cairo University (Approval number: 16/10/35).

\section{Patient allocation and randomization: (Random sequence generation)}

All patients have been fulfilled the prerequisite selection criteria, the 16 patients were randomly assigned into two identical groups each of which eight patients using especial web site concerned with randomization process called research randomizer (https://www.randomizer.org), randomization process performed twice to ensure equal proportions of male and female ratio between both groups.

Group I:Eight patients were treated with conventional RPD.

Group II:Eight patients were treated with a new design of extracoronal castable precision attachment (OT unilateral Rhein 83, Bologna, Italy).

\section{Prosthetic preparation}

Group I: Preliminary impressions were made using alginate impression, the cast was surveyed on the surveyor to locate desirable undercut.

\section{Design of prosthesis}

The design follows the principle of cross arch stabilization of the prosthesis through lingual bar major connector retained by a double Aker clasp at the dentulous side and gingival approaching clasp on the last abutment tooth (RPI) on the edentulous side. The double Aker clasp was placed on the first and second molar and cingulum rest on canine, which acts as an indirect retainer. Preparation of natural teeth and final impression (Figure 1a and b) was taken with alginateimpression material on a special tray.
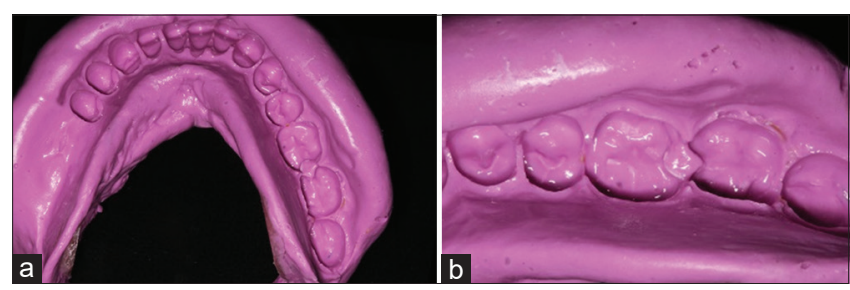

Figure 1: (a) Final impression. (b) Zoom in to show rest seat preparation

The impression was poured in dental stoneto obtain a master cast, and the master cast was surveyed to revise primary surveying. The master cast was modified and duplicated into the refractory cast. On the refractory cast, wax pattern of the RPD framework was built up according to the previous design. Altered cast impression for the distal extension area was made. The framework with the impression was accurately re-seated on the cast. Sticky wax was used to fix the relation of the metal framework to its cast. The final impression was then beaded, boxed, and the edentulous ridge area was poured into improved stone. A face bow record was obtained by maxillary face bow; this record was used to mount the maxillary cast on a semi-adjustable articulator. Centric occlusion relation was registered by the wax wafer method. Anatomical crosslinked acrylic teeth were set up, and try-in was carried out in the patient's mouth; then flasking, processing, deflasking, and finishing of the RPD were done.

Group II: Patients of this group were treated with unilateral RPD retained by OT unilateral extracoronal attachment in which the intact side of the lower arch did not receive any preparation and the experimental side received preparation of the last abutments (first and second premolars) (Figure 2).

\section{Location and orientation of OT unilateral attachment}

A pencil was used to delineate the crest of the residual ridge on the cast. Micro OT CAP parallometer 


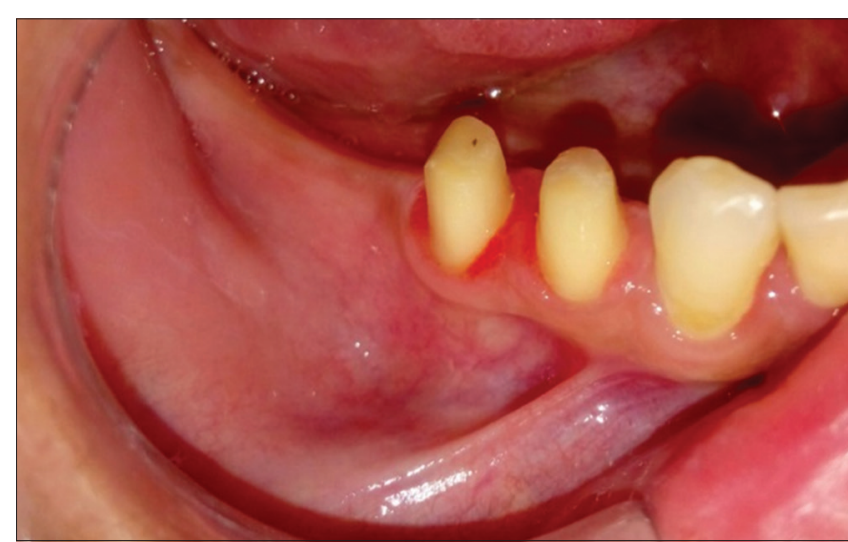

Figure 2: Prepared first and second premolars

mandrel was used to take the attachment from the kit and insert it into the mandrel tip carefully without squeezing the attachment between the mandrel head. Then, the mandrel was connected to parallometer to position the attachment little to the lingual aspect of the ridge to improve esthetics in final restoration and to beast functionality, the attachment was positioned carefully and fixed with wax (Figure 3 ).

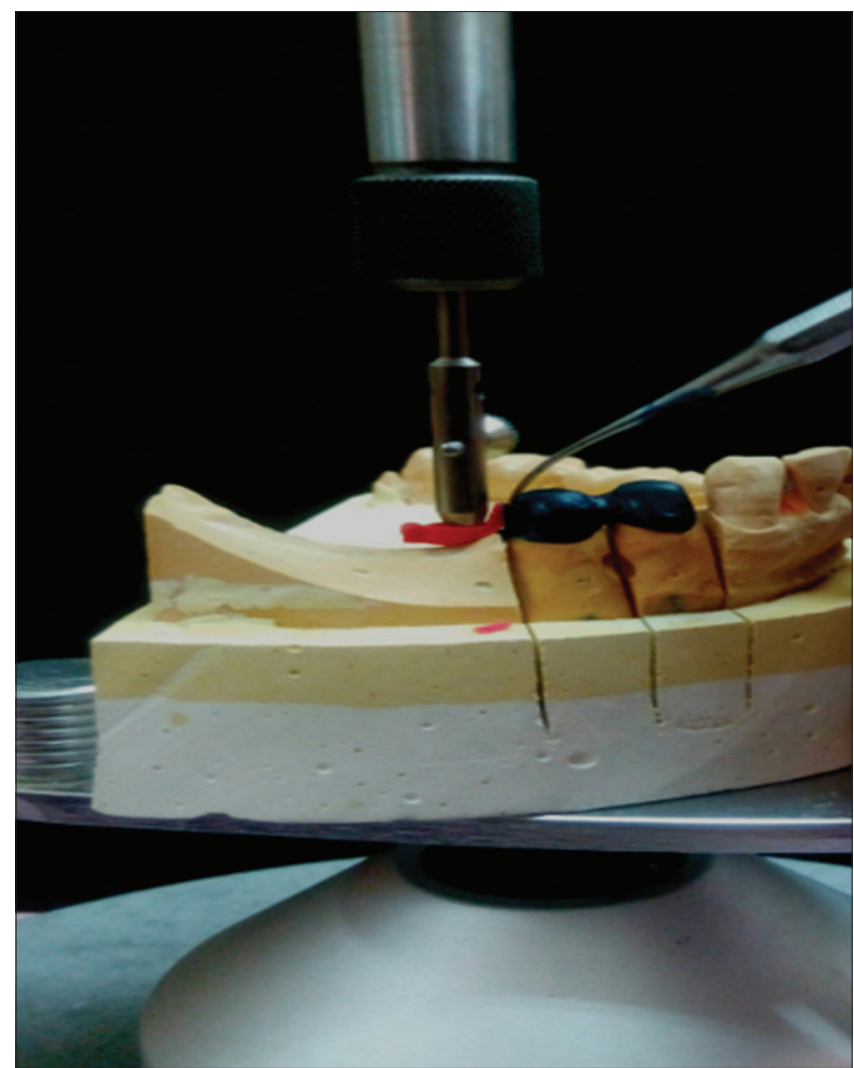

Figure 3: Positioning the OT unilateral attachment using OT CAP paralleling mandrel and fixation of attachment with wax

The layer of wax was adapted on the cast residual ridge before applying the saddle and then, joining the castable saddle to UNI Box by wax, the completed wax pattern was sprued, invested, and cast into a metal framework and crowns attachment assembly (Figure $4 a$ and b).

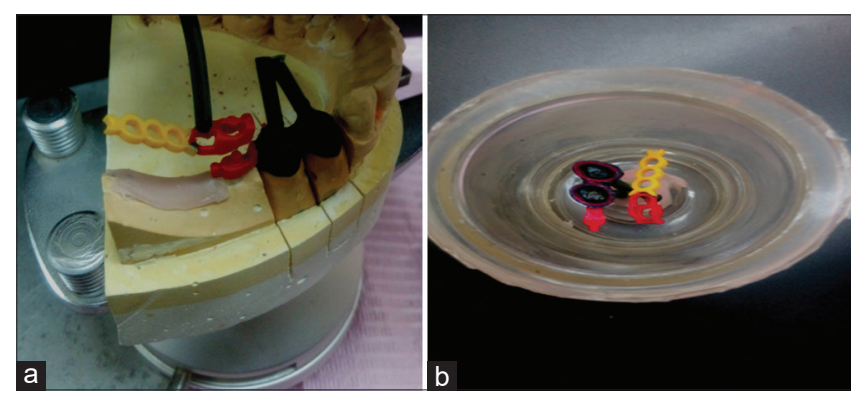

Figure 4: (a) Wax pattern sprued. (b) Wax pattern invested

A face bow record was obtained by maxillary face bowto mount maxillary cast on semi adjustable articulator (Bio-art, Brazil.). Centric occlusion relation was registered by wax wafer method. The porcelain shade was then selected to match the remaining natural teeth; then, the porcelain was built on the two metal crowns.

Acrylic teeth were set up and try-in was carried out in the patient's mouth. The crowns-attachment assembly was finally cemented using glass ionomer cement, and the patient was asked to come the next day for the final placement of the RPD (Figure 5a and b).

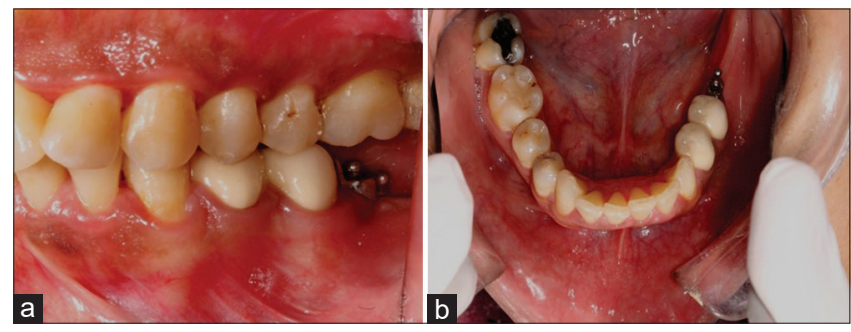

Figure 5: (a) Lateral view of crown attachment assembly. (b) Occlusal view of crown attachment assembly

Base saddle was processed into heat cure acrylic resin and inserted the retentive nylon caps into the frame using the caps inserting tool (Normo/Micro) size, the retentive caps were replaced once a year (Figure 6a and b).

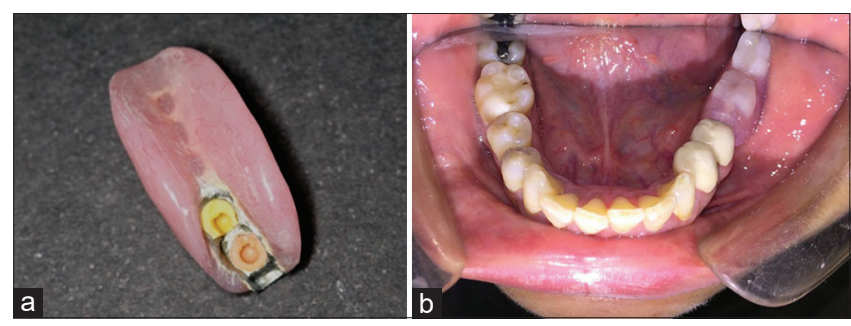

Figure 6: (a) Fitting surface of final prosthesis. (b) Occlusal view of final prosthesis

\section{Evaluation of biting force}

Using loadstar sensor device (Ravendale Drive, mountain view CA 94043 USA), the patient biting force was measured at baseline, 3 months, 6 months, and 12 months intervals. As a preparatory phase for the bite force measurement, the sensor was placed for $12 \mathrm{~h}$ in the measuring environment at room temperature. The 
sensor was then connected to the computer through USB cable during the measurement procedure. The device was allowed to warm by connecting it to power supply for at least $30 \mathrm{~min}$ before the measurement procedure. Temperature fluctuations were avoided using air conditioner of the measuring room at constant temperature during all measurements $\left(25^{\circ} \mathrm{C}\right)$. The patient was seated in an upright position. The load sensor was placed horizontally at the first molar area. The patient was instructed to clench maximally, whereby the direction of the applied force was vertical.

\section{Statistical analysis}

Statistical analysis was done by Microsoft Excel $^{\circledR} 2016$ (Microsoft Cooperation, USA), Statistical Package for the Social Sciences (SPSS) ${ }^{\circledR}$ Ver. 24 (IBM Product, USA) and Minitab(Minitab LLC, USA) ${ }^{\circledR}$ statistical software Ver. 16. Data were revealed as the mean and standard deviation for further analysis. Performing one-way analysis of variance (ANOVA) followed by Tukey's post hoc test to compare between all follow-up periods within each group, comparison between two groups regarding each follow-up period was performed by independent t-test.

The level of significance was considered significant at $p \leq 0.05$.

\section{Results}

\section{Group I (conventional RPDs)}

In Group I mean and standard deviation of occlusal load were $50.9 \pm 2.82,65.7 \pm 3.6,75.05 \pm 3.27$, and $76.5 \pm 2.67$ at time of insertion, after 3 months, after 6 months, and after 12 months respectively.

Performing one-way ANOVA revealed that there is a significant difference between all follow-up periods as $p<0.05$, followed by Tukey's post hoc test that revealed that there is a significant difference between means with the different superscript letters (time of insertion and after 3 months) and (time of insertion and after 6 months) and (after 3 months and after 6 months) as $p<0.05$, while there insignificant difference between means with same superscript letters (after 6 months and after 12 months) as $p>0.05$, as listed in Table 1 .

Table 1: Mean and standard deviations of occlusal load of Group I among follow up periods

\begin{tabular}{|c|c|c|c|c|c|}
\hline & \multicolumn{2}{|c|}{ Conventional } & \multicolumn{2}{|l|}{ Natural } & \multirow[t]{2}{*}{$p$ value } \\
\hline & $\mathrm{M}$ & SD & $\mathrm{M}$ & SD & \\
\hline At time of insertion & $50.9^{\mathrm{a}}$ & 8.8 & $184.6^{\mathrm{a}}$ & 17.1 & $0.0001^{\star *}$ \\
\hline After 3 months & $65.7^{\mathrm{b}}$ & 3.60 & $185.1^{\mathrm{a}}$ & 16.3 & $0.0001^{\text {** }}$ \\
\hline After 6 months & $75.05^{c}$ & 3.27 & $186.9^{\mathrm{a}}$ & 16.9 & $0.0001^{\text {** }}$ \\
\hline After 12 months & $76.5^{\mathrm{c}}$ & 2.67 & $187.2^{\mathrm{a}}$ & 17.3 & $0.0001^{* \star}$ \\
\hline $\mathrm{p}$ value & $0.000^{\star *}$ & & $0.9^{*}$ & & \\
\hline
\end{tabular}

\section{Group II (OT unilateral attachment)}

In Group II mean and standard deviation of occlusal load were $60.3 \pm 3.3,99.4 \pm 3.62 .8,121 \pm 3.1$, and $122.3 \pm 2.9$ at time of insertion, after 3 months, after 6 months, and after 12 months, respectively.

Performing one-way ANOVA revealed that there was a significant difference between all follow-up periods as $p<0.05$, followed by Tukey's post hoc test that revealed that there is a significant difference between means with the different superscript letters (time of insertion and after 3 months) and (time of insertion and after 6 months) and (after 3 months and after 6 months) as $p<0.05$, while there insignificant difference between means with same superscript letters (after 6 months and after 12 months) as $p>0.05$, as listed in Table 2.

Table 2: Mean and standard deviations of occlusal load for all areas of Group II among follow-up periods

\begin{tabular}{|c|c|c|c|c|c|}
\hline & \multicolumn{2}{|c|}{ OT attachment } & \multicolumn{2}{|l|}{ Natural } & \multirow[t]{2}{*}{$p$ value } \\
\hline & $\mathrm{M}$ & SD & $\mathrm{M}$ & SD & \\
\hline At time of insertion & $60.3^{\mathrm{a}}$ & 9.7 & $221.1^{\mathrm{a}}$ & 49.9 & $0.0001^{* \star}$ \\
\hline After 3 months & $99.4^{\mathrm{b}}$ & 2.8 & $222.2^{\mathrm{a}}$ & 48.4 & $0.0001^{* \star}$ \\
\hline After 6 months & $121^{\circ}$ & 3.1 & $222.8^{\mathrm{a}}$ & 50.1 & $0.0001^{* *}$ \\
\hline After 12 months & $122.3^{\mathrm{c}}$ & 2.9 & $223.1^{\mathrm{a}}$ & 49.5 & $0.0001^{* \star}$ \\
\hline$p$ value & $0.0001^{* \star}$ & & $0.9^{*}$ & & \\
\hline
\end{tabular}

\section{Comparison between Group I and Group II}

The mean and standard deviation of all follow-up periods for Groups I and II was compared using independent t-test, which revealed a significant difference between both groups as $p<0.05$, as listed in Table 3.

Table 3: Comparison between both groups regarding mean differences and standard deviations of occlusal load for all areas at all follow-up periods

\begin{tabular}{|c|c|c|c|c|c|}
\hline & \multicolumn{2}{|c|}{ Group I } & \multicolumn{2}{|c|}{ Group II } & \multirow[t]{2}{*}{$p$ value } \\
\hline & $M$ & SD & $M$ & SD & \\
\hline At time of insertion & 50.9 & 8.8 & 60.3 & 9.7 & $0.06^{*}$ \\
\hline After 3 months & 65.7 & 3.60 & 99.4 & 2.8 & $0.0001^{\star \star}$ \\
\hline After 6 months & 75.05 & 3.27 & 121 & 3.1 & $0.0001^{\star *}$ \\
\hline After 12 months & 76.5 & 2.67 & 122.3 & 2.9 & $0.0001^{* *}$ \\
\hline
\end{tabular}

\section{Discussion}

In general, the simplest the design of the partial denture, the better the results. This means that every component of the partial denture must have a good reason for its presence; otherwise, it must be omitted. Applying this principle to this study, it is better to use the unilateral design, because after 12 months, Group II (unilateral design) showed statistically significantly higher biting force than Group I (conventional design), this fact may be attributed to the special design of the OT Unilateral attachment and its resiliency, the presence of two balls in different planes help to distribute the load more favorably under masticatory force and gives best advantage of OT strategy and OT cap in a single elastic solution. 
Biting force measurement can be used as a parameter indicating the functional condition of the masticatory system [10], the results in our study revealed a significant increase in Group I and Group II with time from baseline to 12 months follow-up. This increase in biting force was more prominent when baseline compared to 12 months in both groups. The explanation for this may be attributed to the gradual building up experience and patient adaptation to the new prosthesis. This was in agreement with the results recorded by Van Kampen et al. 2004 [11], who concluded that regardless of the type of prosthesis, patients usually function with their prosthesis much better after sometime.

In this current study, the biting force follow-up of the unilateral attachment group was closer to that of natural teeth value than the conventional group. Although the difference between the two groups is statistically significant, both groups are still less than natural teeth value, which shows a statistically significant increase; this is in agreement with Al-Zarea 2014 [12], which compares unilateral fixed prosthetic treatment with dentate side.

However, there was insignificant difference in the unilateral attachment group from 6 months to 12 months that was attributed to wear of the retentive nylon caps that make patients fear from the loss of retention and stability.

When the biting force of Group I and Group II compared, the results revealed a statistically significant difference in preference of Group II (unilateral attachment design) at the following intervals 3,6 , and 12 months. To clarify this significant increase between two groups, many logic causes may be act in combination:

First, the presence of unilateral attachment revealed increase prosthesis stability, retention, comfort, and more ability to bite without fear from the loss of retention, thus increase masticatory performance in the form of biting force. Second, due to the patient's confidence which was more apparent in unilateral attachment group than conventional group that led to exert more biting force. Another explanation of biting force increase as attachment aid in the establishment of better neuromuscular coordination by improving support, stability and retention of the prosthesis, muscle activity was directed toward masticatory function and no effort was required to stabilize or retain the prosthesis, this is in agreement with Heckmann et al., 2009 [13].

In another word, patients wearing conventional prosthesis usually show the lowest biting forces because bearing tissues are subjected to compression, and the prosthesis may shift during function; this is in agreement with Rosa 2012 [14].

At baseline (time of insertion) there was an insignificant difference between two groups that were attributed to this time of early adjustment period.
Although the differences in biting force between males and females were reported by many studies that explained by hyperactivity of masseter muscle in males than that of females [10]. However, in our study, this factor effect was minimal because the randomization process produced equal gender distribution.

\section{Conclusion}

From the results of this study, it was concluded that; its preferable to use the new design of extracoronal castable precision attachment (OT unilateral) being simpler, more comfortable to the patients and gives high masticatory efficiency in the form of biting force than conventional RPD.

\section{References}

1. Liu R, Kaleinikova Z, Holloway JA, Campagni WV. Conversion of a partial removable dental prosthesis from Kennedy Class II to Class III using a dental implant and semiprecision attachments. J Prosthodont. 2012;21(1):48-51. https://doi. org/10.1111/j.1532-849x.2011.00769.x

PMid:21985475

2. Mc Craken's Removable Partial Denture Prosthodontics. $12^{\text {th }}$ ed. Missouri, United States: (C) Mosby; 2010. p. 12.

3. Gharehchahi J, Asadzadeh N, Mirmortazavi A, Shakeri MT. Maximum dislodging forces of mandibular implant-assisted removable partial dentures: In vitro assessment. J Prosthodont. 2013;22(7):543-9. https://doi.org/10.1111/jopr.12048

PMid:23551954

4. Sato M, Suzuki Y, Kurihara D, Shimpo H, Ohkubo C. Effect of implant support on mandibular distal extension removable partial dentures: Relationship between denture supporting area and stress distribution. J Prosthodont Res. 2013;57(2):109-12. https://doi.org/10.1016/j.jpor.2013.06.002

PMid:23582267

5. Wismeijer D, Tawse-Smith A, Payne AG. Multicentre prospective evaluation of implant-assisted mandibular bilateral distal extension removable partial dentures: Patient satisfaction. Clin Oral Implants Res. 2013;24(1):20-7. https:// doi.org/10.1111/j.1600-0501.2011.02367.x

PMid:22111809

6. Burns DR, Ward JE. Review of attachments for removable partial denture design: 1. Classification and selection. Int $\mathrm{J}$ Prosthodont. 1990;3(1):98-102.

PMid:2196898

7. Burns DR, Ward JE. A review of attachments for removable partial denture design: Part 2. Treatment planning and attachment selection. Int J Prosthodont. 1990;3(2):169-74. PMid:2133384

8. Jain AR, Philip JM, Padma A. Attachment-retained unilateral distal extension (Kennedy's Class II Modification I) cast partial denture. J Prosthet Dent. 2012;2:101-3. https://doi.org/10.5005/ jp-journals-10019-1057

9. Domer M, Abbas NA, Wahab EA. Retention of Two Extra Coronal 
Attachments Incorporated with Distal Extension Removable Partial Dentures (in vivo study) Master Thesis Eygpt. Giza, Egypt: Cairo University; 2010.

10. Koc D, Dogan A, Bek B. Bite force and influential factors on bite force measurements: A literature review. Eur J Dent. 2010;4(2):223-32. https://doi.org/10.1055/s-0039-1697833 PMid:20396457

11. van Kampen FM, van der Bilt A, Cune MS, Fontijn-Tekamp FA, Bosman F. Masticatory function with implant-supported overdentures. J Dent Res. 2004;83(9):708-11. https://doi. org/10.1177/154405910408300910

PMid:15329377
12. Al-Zarea BK. Maximum bite force following unilateral fixed prosthetic treatment: A within-subject comparison to the dentate side. Med Princ Pract. 2015;24(2):142-6. https://doi. org/10.1159/000370214

PMid:25612783

13. Heckmann SM, Heussinger S, Linke JJ, Graef F, Pröschel P. Improvement and long-term stability of neuromuscular adaptation in implant-supported overdentures. Clin Oral Implants Res. 2009;20(11):1200-5. https://doi. org/10.1111/j.1600-0501.2009.01722.x PMid:19832766

14. Rosa LB. Bite force and masticatory efficiency in individuals with different oral rehabilitations. Open J Stomatol. 2012;2:21-6. 